\title{
El proceso legislativo en el Tratado de Lisboa: privilegio de la eficacia en detrimento de la democracia*
}

\section{The Legislative Process in the Lisbon Treaty: Privilege of Effectiveness in Detriment of Democracy}

\author{
Ma. Catalina Micolta Portocarrero ${ }^{* *}$
}

Recibido: 10/01/2014

Aprobado Evaluador Interno: 29/01/2014

Aprobado Evaluador Externo: 16/02/2014

\section{Resumen}

El déficit democrático que adolece la Unión Europea se traduce en una serie de cuestionamientos con respecto a la legitimidad democrática en los procesos de toma de decisiones a nivel comunitario. Aunque son diversos los factores que intervienen para que éste se configure, el presente estudio sólo se centra en el análisis de dos aspectos fundamentales: por una parte, la debilidad institucional del Parlamento Europeo frente al predominio del Consejo en el proceso de aprobación legislativa en la UE; y por otra, la opacidad de dicho proceso, hecho que dificulta la correcta información de los ciudadanos comunitarios y que además impide la aplicación de mecanismos de rendición de cuentas. Para hacer frente a estos cuestionamientos, el Tratado de Lisboa incorpora una serie de reformas que buscan tanto el fortalecimiento del Parlamento

\section{Abstract}

The democratic deficit in the European Union proposes a series of questions about democratic legitimacy in decision-making processes at the community level. Although there are different factors involved which configure this democratic deficit, this study only focuses on the analysis of two aspects: on the one hand, the institutional weakness of the European Parliament against the Council predominance in the process of legislative approval in the EU, and, on the other, the opacity of this legislative process, which hinders the correct information of EU citizens and also prevents the implementation of accountability mechanisms. To address these questions, the Lisbon Treaty makes a number of reforms and new additions that seek both to strengthen the European Parliament into the legislative process

doi:10.11144/Javeriana.PAPO19-1.plt|

* Artículo de reflexión.

** Politóloga con énfasis en Relaciones Internacionales de la Pontificia Universidad Javeriana. Estudiante de la Maestría en Relaciones Internacionales de la Pontificia Universidad Javeriana. Correo electrónico: cataportocarrero@gmail.com 
Europeo al interior del procedimiento legislativo como la publicidad de los procesos deliberativos al interior del mismo; sin embargo en este estudio se señala cómo el desarrollo de una serie de mecanismos de negociación de carácter informal al interior del procedimiento legislativo no sólo hacen insuficientes estas incorporaciones, sino que además profundizan el deterioro democrático en la UE.

\section{Palabras clave:}

Unión Europea; Tratado de Lisboa; déficit democrático; proceso legislativo and the public deliberative processes within it; however, this study shows how the development of a series of negotiation mechanisms of an informal nature into the legislative process not only make insufficient the additions of the Lisbon Treaty to overcome the problem of the democratic deficit, but also deepens the democratic deterioration in the EU.

\section{Keywords:}

European Union; Lisbon Treaty; democratic deficit; legislative process 


\section{Introducción}

Desde sus inicios, lo que hoy conocemos como la Unión Europea (UE) no había planteado mayores interrogantes sobre su legitimidad democrática, era claro que ésta emanaba de la autonomía de cada uno de sus Estados miembros. Sin embargo, a medida que se va ampliando y profundizando el proceso de integración, el tema de la legitimidad democrática empieza a cobrar importancia, particularmente hacia finales de los años $80 \mathrm{y}$ comienzos de los 90 con la firma del Acta Única Europea (AUE) y el Tratado de la Unión Europea (TUE o Tratado de Maastricht); de esta manera, la complejidad que alcanza el proceso de integración hace que empiecen a surgir cuestionamientos en ese sentido sobre la estructura institucional y el funcionamiento de la UE, y que dichos objeciones se traduzcan en demandas sobre la necesidad de democratización del proyecto europeo.

Estos cuestionamientos han hecho énfasis, entre otros aspectos, en dos elementos que impactan la legitimidad democrática de la UE: por una parte, lo que se ha denominado como debilidad institucional del Parlamento Europeo (PE) frente al predominio del Consejo en el proceso de aprobación legislativa en la UE; y por otra, la misma opacidad del proceso legislativo, hecho que dificulta la correcta información de los ciudadanos y que impide la aplicación de mecanismos de rendición de cuentas.

La última reforma realizada a los tratados de la UE pretende hacerle frente a este tipo de cuestionamientos. Así, el Tratado de Funcionamiento de la Unión Europea (TFUE) busca en su contenido fortalecer el papel del PE al interior de la estructura institucional y del mismo proceso legislativo en la UE aumentando el número de asuntos comunitarios que deberán ser aprobados mediante el proceso legislativo ordinario (anterior proceso de codecisión), lo que permite, en principio, poner en pie de igualdad al PE en relación al Consejo en el proceso legislativo. Asimismo, el TFUE exige que los procesos deliberativos en las diferentes etapas del procedimiento legislativo ordinario, tanto al interior del PE como del Consejo, sean de carácter público con el objeto de que los ciudadanos comunitarios puedan "participar" en él en aras de una mayor transparencia en el proceso de aprobación legislativa. De igual manera, el TFUE busca fortalecer el papel de los parlamentos nacionales al interior del proceso legislativo en la UE. En ese sentido, el TFUE estipula el incremento en el intercambio de información entre estos y el PE durante todas las fases del proceso legislativo ordinario e incorpora un mecanismo de seguimiento temprano que les permite a los parlamentos nacionales verificar si una propuesta de la Comisión quiebra el principio de subsidiariedad. ${ }^{1}$

1 "En virtud del principio de subsidiariedad, en los ámbitos que no sean de su competencia exclusiva, la Unión intervendrá sólo en caso de que, y en la medida en que, los objetivos de la acción pretendida no puedan ser alcanzados de manera suficiente por los Estados miembros, ni a nivel central ni a nivel regional y local, sino que puedan alcanzarse mejor, debido a la dimensión o a los efectos de la acción pretendida, a escala de la Unión." (Art. 5.3 TUE ). 
Sin embargo, al examinar de cerca el proceso legislativo ordinario se ha encontrado que las instituciones que en él participan han desarrollado de manera paralela a los mecanismos formales, una serie de mecanismos informales de negociación al interior del procedimiento. Desde la incorporación del Tratado de Ámsterdam se permite que tanto representantes del PE como del Consejo y la Comisión, sostengan reuniones al margen de cada uno de los foros para negociar compromisos sobre temas que serán objeto del proceso legislativo, esto con el propósito de hacer más eficaz dicho proceso.

En razón de lo anterior, y atendiendo las justificaciones que se dan en el marco del TFUE sobre la necesidad de mejorar la calidad democrática de la UE, el propósito de este estudio es examinar si las reformas incorporadas por el Tratado de Lisboa permiten superar el déficit democrático en el desarrollo del proceso legislativo al interior de la UE. Para esto, el trabajo se dividió en las siguientes partes. Una dedicada a una aproximación teórica en la que, por una parte, se abordan los principales supuestos del Federalismo e Intergubernamentalismo, los cuales permiten dar cuenta del proceso de integración europea desde su dimensión política; y por otra, desde la teoría política se explican las características y elementos de la democracia representativa. La segunda parte del trabajo hace una amplia revisión sobre la conceptualización, configuración y las distintas posiciones respecto al déficit democrático en la UE. La tercera describe las competencias legislativas en la UE, la función del PE dentro del proceso legislativo, el desarrollo del procedimiento legislativo ordinario consagrado en el actual TFUE, y se realiza una exposición de las prácticas informales en las que las instituciones que intervienen en dicho procedimiento se ven involucradas y afectan la legitimidad democrática del proceso legislativo. La cuarta realiza un análisis del contenido del TFUE exponiendo las principales reformas que introduce sobre el procedimiento legislativo ordinario y examinándolas a la luz de las prácticas informales. Finalmente, se encuentra el apartado de conclusiones.

\section{Federalismo, Intergubernamentalismo y Democracia Representativa: elementos conceptuales y de reflexión sobre la legitimidad democrática en la UE}

La gradual profundización política de la integración europea ha planteado importantes retos en relación a su legitimidad democrática. El aumento del traslado de competencias a nivel supranacional genera un impacto directo sobre los ciudadanos comunitarios, quienes ya no cuentan con los mecanismos clásicos de control democrático que operan al interior de los Estados, pues a nivel supranacional estos son insuficientes.

La comprensión de déficit democrático en la Unión Europea requiere de una aproximación teórica que dé cuenta del proceso de integración europeo desde su dimensión política. Por ello, a continuación se exponen las premisas conceptuales de dos de las principales teorías de la integración europea, el federalismo y el intergubernamentalismo, cuyos aportes permiten una detallada observación y comprensión 
del funcionamiento institucional y de los procedimientos en la toma de decisiones a nivel comunitario. Por una parte, el federalismo facilita una aproximación al significado del proyecto de integración europeo desde lo político, haciendo posible un mejor examen e interpretación del déficit democrático a través de la naturaleza, funcionamiento y relaciones entre las instituciones supranacionales europeas como son la Comisión, el Consejo y particularmente el Parlamento Europeo. Por otra parte, el intergubernamentalismo permite comprender la lógica de los procesos de toma de decisiones al interior de la Unión Europea, principalmente en el análisis de las competencias legislativas en la Unión Europea y el rol que desempeña el Parlamento Europeo al interior de las mismas. De manera particular, el intergubernamentalismo contribuye a establecer el porqué del privilegio de las instituciones que dependen directamente de los Estados y con ello a examinar claramente en qué consiste la debilidad institucional del Parlamento Europeo.

Desde la teoría política, y como complemento indispensable, se explican las características y elementos de la democracia representativa como el modelo que permitirá analizar de qué manera se configura el déficit democrático en el proceso legislativo de la Unión Europea.

\section{Federalismo}

El federalismo no sólo es considerado una teoría sino también un movimiento ideológico cuya presencia se ha destacado durante los dos últimos siglos. La concepción moderna del modelo federal como forma de organización política emerge en los Estados Unidos de Norteamérica ${ }^{2}$ y su experiencia nutre los principales movimientos federalistas europeos que cobran fuerza durante el periodo de la posguerra, los cuales ayudan a impulsar el proyecto de integración europea. ${ }^{3}$

Desde el punto de vista teórico, y de acuerdo con Daniel Elazar (en Cancela, 2001), el federalismo no puede ser entendido como un concepto unívoco sino como un valor clásico, lo que permite asumir a su vez el carácter dinámico del mismo. En ese sentido afirma Carl Friedrich: "Es decisivo que se capte el dinamismo de su funcionamiento: el federalismo requiere e implica un proceso de federalización; es un proceso incesante, en el cual la mutua relación y adaptación entre las comunidades componentes claramente

\footnotetext{
${ }^{2}$ La concepción moderna del federalismo se construye en el proceso de ratificación de la Constitución de los Estados Unidos de Norteamérica, cuya promoción liderada por Madison, Hamilton y Jael a través de los Federalist Papers, aboga por una organización política compuesta por una diversidad de individuos libres y autónomos quienes pactan el establecimiento de instituciones políticas federales (Elazar, 1993).

${ }^{3}$ Entre estos movimientos se destacan la Unión Europea de Federalistas (1946) y la Unión Parlamentaria Europea (1947), los cuales buscan la construcción de una unión de Europa concebida y organizada de manera federal que limite la soberanía de los Estados y garantice valores democráticos (Mariscal, 2003).
} 
diferenciadas y la comunidad incluyente está continuamente sobre el tapete" (1973, p. 43). De esta manera, el federalismo en tanto que proceso no permite una sola definición y tampoco una manera única de manifestación, pues serán las dinámicas adaptativas entre las comunidades componentes y la comunidad incluyente las que se sirvan dar forma a la organización federal.

La mayor parte de la literatura sobre el Federalismo concuerda en afirmar que la característica fundamental de éste es la unión en la diversidad, unión que se fundamenta en la consecución de unos objetivos comunes manteniendo siempre la aceptación de las diferencias que caracterizan a las colectividades que la componen. Esta relación no puede ser vista como dicotómica, en la que la presencia de un elemento niega la existencia del otro, sino que debe ser entendida como una relación complementaria (Mariscal, 2003). En el mismo sentido, como afirma Celso Cancela (2001): “...el federalismo busca armonizar la creación de una entidad política común con el mantenimiento de una cierta capacidad de autogobierno o autonomía de sus integrantes" (p. 46)

En El futuro federalista de Europa, Sidjanski enuncia los principios y virtudes del federalismo ya expuestos por Denis de Rougemont:

En primer lugar, la renuncia a la hegemonía, la renuncia a la idea de sistema porque federar es reunir elementos heteróclitos. El federalismo no conoce problemas de minorías: el objetivo de una federación es salvaguardar la cualidad propia de cada minoría; de la misma forma que lo es la preservación de la cualidad propia de las naciones o de los estados federados, o de las regiones federadas. Además el federalismo se basa en el amor a la complejidad: es lo contrario a la simplificación totalitaria, a la uniformidad impuesta por el poder central. En realidad, una federación se forma poco a poco por medio de las personas y los grupos. Nace y crece en un espacio de libertad, de democracia y de pluralismo, en la multiplicidad de ideas, de culturas, de partidos y de regiones y en un tejido socialmente complejo y diversificado. El federalismo evoca la corriente que circula de abajo hacia arriba. [...] Como la región, el federalismo es natural y funcional y no es el resultado de una obligación artificial (1998, p. 220).

Los anteriores principios encuentran su correspondencia en aquellos propuestos por Guy Héraud: 1) La autonomía como "atributo de todo ser, individuo o colectividad”; 2) La exacta adecuación que corresponde al reparto de competencias entre los diferentes niveles según su naturaleza; 3) La participación que hace referencia a la "asociación activa de las colectividades componentes a la toma de decisiones de la colectividad compuesta. [...] Gracias a la participación, la colectividad superior es verdaderamente democrática"; 4) La cooperación que permite coordinar decisiones consentidas; 5) La complementariedad en la que "aquello que es bueno o malo para la colectividad compuesta es respectivamente bueno o malo para las colectividades componentes.; y 6) La 
garantía sobre las competencias, tanto en su efectiva utilización como sobre el control frente a posibles excesos." (Mariscal, 2003, pp. 69-72).

Retomando la característica esencial del federalismo, la cual consiste en lograr la unidad manteniendo la diversidad, se encuentra el punto de partida para afirmar que el proceso de construcción de la integración en la Unión Europea puede entenderse como una manifestación del federalismo. Desde el punto de vista histórico, este proceso de integración se ha visto marcado por una clara vocación federal. Desde el diseño de las primeras Comunidades Europeas, el fin federalista ha sido expuesto de manera explícita como se ve en la Declaración de Robert Schuman del 9 de mayo de 1950: "La puesta en común de las producciones de carbón y de acero garantizará inmediatamente la creación de bases comunes de desarrollo económico, primera etapa de la federación europea, y cambiará el destino de esas regiones, que durante tanto tiempo se han dedicado a la fabricación de armas, de las que ellas mismas han sido las primeras víctimas" (2006, p. 114). Otro ejemplo se observa en la ponencia presentada por Jean Monnet ante la Comisión Randall el 11 de noviembre de 1953 en la ciudad de Paris:

Se toca aquí el principio fundamental de la creación de Europa: la transferencia, realizada con toda libertad, de poderes soberanos por naciones que han subsistido hasta el momento sólo sobre la base de su soberanía nacional y que delegan ahora una parte de ésta en instituciones comunes que la ejercerán en su nombre. [...] la forma de esta revolución democrática y pacífica que Europa está sufriendo actualmente desembocará en la creación de los Estados Unidos de Europa. (2008, p. 42).

Igualmente, hay que destacar que el proceso de integración europea se ha ido construyendo de manera espontánea y en función de sus necesidades, lo cual se refleja en la misma evolución a través del tiempo de lo que fuera en un principio las primeras Comunidades Europeas (CECA, EURATOM Y CEE) hasta llegar a lo que se conoce hoy en día como Unión Europea.

Desde el punto de vista práctico, se confirman importantes elementos del federalismo en la Unión Europea, como la definición de la identidad europea a través del principio de unidad en la diversidad (Sidjanski, 1998, p. 213) así como elementos institucionales y materiales como la existencia de un gobierno compartido, una división territorial de poderes entre diferentes niveles de gobierno como son el europeo, el estatal y el regional, la instauración de un conjunto de instituciones comunes a las que han conferido ciertos poderes (traspaso de soberanía en determinadas áreas) y por supuesto, la presencia de valores compartidos como la democracia, el respeto a los derechos fundamentales, la economía de mercado y el bienestar social sobre los cuales se fundamenta la necesidad de alcanzar objetivos comunes como la paz, la seguridad, la prosperidad y el bienestar 
(Cancela, 2001). De igual manera, es necesario resaltar que la creación y desarrollo del Parlamento Europeo como institución comunitaria tiene una gran significación política que refleja la naturaleza federal de la Unión Europea como se argumentará en el apartado dedicado al papel del Parlamento Europeo en las competencias legislativas de la Unión...

Frente al problema del déficit democrático en la Unión Europea, el federalismo se revela como una solución al mismo, ya que el elemento participativo es uno de sus principios fundamentales y su garantía permite el fortalecimiento y desarrollo de otros principios como son la libertad y la democracia. De igual forma, permite profundizar en materia democrática al interior de la Unión Europea ya que la evolución en el diseño institucional de ésta deberá estar dirigida no sólo a reducir la distancia entre los ciudadanos comunitarios y las instituciones sino también al fortalecimiento de la institución de representación política por excelencia, el Parlamento Europeo.

\section{Intergubernamentalismo}

El Intergubernamentalismo surge a finales de los años sesenta como reacción a los postulados de las teorías de la integración supranacional, particularmente el funcionalismo y neofuncionalismo, ${ }^{4}$ en las que el papel del Estado-nación queda no sólo relegado sino debilitado por las fuerzas desbordantes de los procesos de integración. En ese sentido, los postulados del Intergubernamentalismo giran en torno a la reivindicación del rol que desempeñan los Estados-nación frente a los procesos de integración.

El principal supuesto de la teoría intergubernamental es que los Estados no sólo son las unidades centrales en el desarrollo de los procesos de integración sino que también se constituyen en los agentes generadores y controladores de dichos procesos. Así lo afirma Stanley Hoffmann:

\footnotetext{
Hasta ahora, la exclusiva transferencia de expectativas de beneficios del Estado-nación hacia una entidad más grande, deja al Estado-nación tanto como el foco principal de estas expectativas, así como el iniciador, líder, supervisor y a menudo destructor de esa entidad más grande: en el ámbito internacional el Estado sigue siendo el mayor poseedor de poder y aunque no todos los Estados son una comunidad política, no existe todavía una comunidad política más incluyente que el Estado. (1966, p. 909)
}

\footnotetext{
${ }^{4}$ Según estas teorías, "los procesos de integración están dirigidos hacia la conformación de una comunidad política supranacional institucionalizada, cuya estructura y capacidad de acción va más allá de una organización internacional pero sin llegar a ser una organización federal" (Mariscal, 2003, p. 27). Los Estados de manera paulatina van perdiendo poder a favor de las instituciones centrales y con ello también se da una transferencia de lealtad hacia estas.
} 
De igual manera, Hoffmann destaca el carácter racional del Estado al comparar entre lo que él denomina la lógica de la integración que propone el neofuncionalismo frente a la lógica de la diversidad propia del intergubernamentalismo, destacando que ésta última se hace visible en los casos en que el proceso de integración toca áreas sensibles al interés nacional dado que los "Estados prefieren la certeza o la incertidumbre autocontrolada de la autoconfianza nacional frente a la incertidumbre no controlada" (1966, p. 882). En ese sentido, es clara la implicación destructiva para los Estados que sugieren implícitamente los procesos de integración supranacional.

De lo anterior se deriva otro aspecto importante del Intergubernamentalismo y es la consideración, frente a los procesos de integración, de la significativa diferencia entre los temas de "baja política" (relacionados con asuntos económicos y sociales) y de "alta política” (relacionados con la seguridad del Estado), señalando que los Estados posibilitan los procesos de integración únicamente para gestionar asuntos de "baja política", ya que "la interdependencia hace prevalecer la solidaridad sobre la competición. Por ello, resulta factible la integración económica” (Hoffmann, en Salomón, 1999, p. 206). Así pues, los procesos de integración suelen desarrollarse en el ámbito económico y no tanto en el ámbito político.

Es evidente que la teoría intergubernamental comparte algunas premisas importantes de la teoría del realismo clásico, pero se aleja de ésta al aceptar el impacto que la interdependencia económica genera sobre la capacidad de acción de los Estados, razón por la cual los procesos de integración representan una utilidad para estos ya que les permite no sólo su permanencia como principal referente de la vida política sino también ayuda a los gobiernos nacionales en el cumplimiento de sus objetivos (Mariscal, 2003). En igual sentido se expresa Andrew Moravcsik ${ }^{5}$ al exponer los efectos de la interdependencia económica sobre los Estados y los mecanismos para enfrentarlos:

El supuesto del comportamiento racional estatal proporciona una marco general de análisis, dentro del cual los costos y beneficios de la interdependencia económica determinan las preferencias nacionales, mientras la intensidad de éstas, las posibles coaliciones alternativas y la vinculación de cuestiones condicionan los resultados distributivos de las negociaciones, y las instituciones supranacionales reducen el costo de las transacciones y fortalecen la autonomía de los líderes nacionales. (1993, p. 480)

\footnotetext{
${ }^{5}$ Andrew Moravcsik es uno de los autores que mayores aportes ha realizado al Intergubernamentalismo. Sus trabajos se han desarrollado a partir del proceso de integración europeo, particularmente el examen de los procesos de negociación de los distintos Tratados a través de las preferencias nacionales de los Estados miembros. Tal es el caso del análisis del proceso de negociación del Acta Única Europea (Moravcsik, 1991) y de los Tratados de Roma y Maastricht (Moravcsik, 1998).
} 
Siguiendo a Moravcsik, los procesos de integración son explicados desde un marco racionalista compuesto por tres momentos: el primero, la formación de preferencias nacionales, entendiendo estas como "un conjunto ordenado y ponderado de los valores asignados a futuros resultados, reales e importantes, llamados a menudo 'estados del mundo' que pudieran derivarse de la interacción política internacional. Estas preferencias reflejan los objetivos de los grupos domésticos que influyen en el aparato estatal” (1998, p. 24). El segundo, las negociaciones interestatales se explican por la heterogeneidad de las preferencias nacionales que hacen necesario emprender negociaciones entre estos para lograr una cooperación mutuamente exitosa (1998). Es necesario precisar, como afirma Moravcsik sobre la Comunidad Europea, que cada gobierno ve a la comunidad que se deriva del proceso de integración a través del lente de sus propias preferencias políticas, lo que significa que "cada política de la Comunidad Europea es la continuación de las políticas domésticas por otros medios” (1991, p. 47). Y finalmente el tercer momento, representado por una elección institucional que permite aumentar la eficiencia de la negociación interestatal mediante la reducción de los costos de identificar, hacer y mantener los acuerdos (1993).

Esta elección institucional supone a su vez una restricción a la soberanía de cada uno de los Estados que participa en el proceso de integración y se puede dar de dos maneras: por una puesta en común, cuando los gobiernos acuerdan decisiones sobre ciertos asuntos mediante mecanismos de votación diferentes al de la unanimidad (un ejemplo es la mayoría cualificada), o por delegación, cuando son las instituciones supranacionales, quienes de manera autónoma, toman las decisiones sin ningún tipo de intervención de los Estados (1998). La manera como se expone esta restricción a la soberanía de los Estados que participan en un proceso de integración en ningún momento supone que estos Estados pierdan control sobre la misma, ya que en los procesos de integración predominan las instituciones intergubernamentales, es decir, instituciones que tienen un control directo por parte de los representantes de los Estados miembros.

La teoría intergubernamental se ha desarrollado de manera casi paralela al proceso de construcción de la integración europea. De manera particular se resaltan dos eventos que permiten evidenciar las explicaciones teóricas que brinda el intergubernamentalismo: por una parte, el Compromiso de Luxemburgo de enero de 1966, a través del cual se facultó a los Estados de un derecho a veto sobre las decisiones tomadas por unanimidad en el Consejo, cuando estas afecten intereses importantes de uno o varios Estados miembros; por otra, la creación del Consejo Europeo ${ }^{6}$ en el año 1974, el cual a través de su evolución hoy determina la dirección y los objetivos de la Unión Europea (Salomón, 1999). Este último

\footnotetext{
${ }^{6}$ Oficializado en 1992 con el Tratado de Maastricht y posteriormente elevado a la categoría de institución comunitaria en el año 2009 con el Tratado de Lisboa.
} 
evento sumado a la función legislativa que posee el Consejo, constatan el privilegio que se otorga al interior de la estructura institucional de la Unión Europea a los órganos que dependen directamente de los Estados, lo que permite explicar el porqué de los avances en materia de integración económica en detrimento de la integración política.

En relación al déficit democrático en la Unión Europea, la tendencia intergubernamental a controlar el proceso de integración europeo ha jugado en contra del real fortalecimiento del Parlamento Europeo como principal órgano de representación política al interior de la Unión Europea. En este orden de ideas, la teoría intergubernamental no sólo permite evidenciar qué hay detrás del funcionamiento del Consejo y de su relación con el Parlamento Europeo y la Comisión Europea en el procedimiento legislativo ordinario, sino que además enriquece el debate a propósito del déficit democrático en la Unión Europea, ya que la teoría del intergubernamentalismo niega su existencia, como se expondrá en el siguiente capítulo.

\section{Democracia Representativa}

La concepción moderna de la democracia está estrechamente vinculada a tres elementos esenciales: la legitimidad del poder basada en el consentimiento de los ciudadanos, el Estado de derecho y la representación política. Respecto al primer elemento, las instituciones políticas occidentales han estado afectadas de manera crucial por el principio de origen romano Quod omnes tangit, ab amnibus tractari et approbari debet (lo que a todos afecta, debe ser tratado y aprobado por todos), ${ }^{7}$ su esencia ayudó a establecer el consentimiento de los gobernados como fuente de legitimidad y aprobación política (Manin, 1998). Con relación al segundo elemento, el Estado de derecho supone la sujeción de la actividad del Estado a una Constitución y las leyes que de ella se derivan, las cuales deben brindar protección a los derechos individuales y garantizar un funcionamiento controlado de los órganos del poder público y de las autoridades que detentan el poder (O’Donnell, 2001). Y finalmente, la representación política como tercer elemento, el cual "parte de la idea de que la unidad política del pueblo como tal nunca puede hallarse presente en identidad real, y por eso tiene que estar siempre representada personalmente por hombres" (Schmitt, citado en Manin, 1998, p. 188).

El concepto de democracia representativa surge a finales del siglo XVIII como un mecanismo que permite superar las demandas de inclusión de todos los ciudadanos en el proceso de determinación de la voluntad colectiva (Bobbio en Held, 2007, p. 143). La imposibilidad material de participación de todos los ciudadanos en los asuntos públicos, permite celebrar a la democracia representativa como "un gobierno responsable

\footnotetext{
${ }^{7}$ En Roma éste principio era aplicado en el derecho privado, pero tras el resurgimiento del derecho romano en el siglo XII empezó a aplicarse a las cuestiones públicas (Manin, 1998).
} 
$\mathrm{y}$ factible, potencialmente estable en grandes territorios y durante largos periodos de tiempo" (Dahl citado en Held, 2007, p. 143).

Retomando los elementos anteriores, una definición formal de democracia representativa apuntaría a establecer que se trata de "un sistema de gobierno en el cual los individuos que desempeñan las funciones de gobierno, sea legislativa o ejecutiva, son representantes de los ciudadanos y de sus intereses; $y$ han sido seleccionados por medio de elecciones, sean estas directas o indirectas" (Preciado, 2008, p. 5). En ese sentido, el elemento democrático de la representación política está dado porque todos los ciudadanos pueden participar como electores a través del sufragio.

Siguiendo a Bernard Manin (1998), en el desarrollo del modelo de democracia representativa se pueden identificar cuatro principios. El primero: "quienes gobiernan son nombrados por elección con intervalos regulares” (p. 218), en ese sentido la periodicidad de las elecciones es el principal incentivo para que los representantes tengan en cuenta la opinión de quienes representan, ya que el voto es el mecanismo que avala o no el desempeño de quienes gobiernan. El segundo: "la toma de decisiones por los que gobiernan conserva un grado de independencia respecto a los deseos del electorado" (p. 205), esto significa que la actividad que desempeñan los representantes no puede ser objeto de un mandato imperativo, ya que estos deben contar con cierto grado de discrecionalidad a la hora de tomar decisiones. Tercero: "los que son gobernados pueden expresar sus opiniones y deseos políticos sin estar sujetos al control de los que gobiernan” (p. 206), de este elemento se desprenden dos consideraciones, por una parte, para que los gobernados puedan hacerse a una opinión sobre las cuestiones políticas deben tener acceso a la información, lo que exige que las decisiones gubernamentales se hagan públicas; y por otra, ésta libertad de opinión de los gobernados podrá manifestarse en cualquier momento, no solo durante las elecciones. Este elemento de la libertad de opinión también recalca el papel político de los ciudadanos, ya que como contrapartida a la imposibilidad de otorgar imperativos a los gobernantes, la expresión de su opinión constituye un mecanismo para que la voz de los gobernados sea escuchada por aquellos que gobiernan. Finalmente, el cuarto elemento consiste en que "las decisiones públicas se someten a un proceso de debate” (p. 233). En la democracia representativa, dicho proceso tiene lugar en un espacio que juega un papel decisivo: la asamblea o parlamento, instancia que refleja la heterogeneidad de la sociedad. Y es precisamente ese carácter heterogéneo, el que le confiere un papel importante al debate (entre igualdad de voluntades) como mecanismo que permite lograr acuerdos a través de la persuasión recíproca y que concluye con el consentimiento de la mayoría. ${ }^{8}$

\footnotetext{
${ }^{8}$ El consentimiento de la mayoría, como afirma Manin (1998), proporciona un principio de toma de decisiones, compatible con las limitaciones temporales a las que están sometidas las acciones políticas.
} 
La descripción de estos principios, si bien da un panorama que permite hacerse una idea sobre la representación política, no ahonda sobre las exigencias que trae consigo dicha representación. El primer principio bajo el cual se describe cómo se nombra a los representantes, es decir mediante el sufragio, ${ }^{9}$ lleva de manera implícita dos elementos fundamentales en la relación entre representantes y representados: la receptividad ${ }^{10} \mathrm{y}$ la responsabilidad. Al elegir mediante el voto a sus representantes, los representados les generan la responsabilidad de actuar conforme a sus intereses y por tanto en su beneficio, ello se desprende de lo que Pitkin ha señalado como representación en términos de una relación sustantiva (citada en García, 2005). Sin embargo, lo expuesto anteriormente podría encontrarse en franca contradicción con el principio de la discrecionalidad de los representantes. Si los representantes - por obvias razones - no pueden ser objeto de un mandato imperativo, ¿cómo determinar entonces qué intereses están protegiendo? La respuesta está en el mismo proceso de representación y en la obligación que tienen los representantes de informar sobre sus decisiones.

Lo anterior, hace visible otro factor fundamental al interior de la representación política y es el concepto de rendición de cuentas. ${ }^{11}$ Como expresa Pitkin "los representantes políticos electos, son verdaderos representantes sólo si dan cuenta de sus actos a aquellos para quienes actúan" (1967, p. 226). Este elemento de la rendición de cuentas se encuentra estrechamente relacionado con los otros dos principios que Bernard Manin (1998) enuncia sobre la representación política: el sometimiento de las decisiones a un proceso de debate y la libre opinión de los gobernados. Sobre el proceso de debate, Mansbridge afirma que "Lo que cobra importancia entonces es el proceso de deliberación (...) durante el cual, las partes se harían más conscientes de las implicaciones de las diferentes opciones en juego, de cuáles son los intereses que están detrás y de cuál es el interés general" (citado en García, 2005, p. 118). Respecto a la libre opinión de los gobernados, se supone que se encuentra mediada por el libre acceso a la información, elemento central, pues como afirma Przeworski "nuestra autorización para gobernar no incluye la autoridad para ocultarnos información” (1998, p. 26), permitiendo que esa libre opinión (informada) funcione también como mecanismo de presión para los gobernantes.

${ }^{9}$ El sufragio en la democracia representativa posee una doble finalidad. Por una parte, es el mecanismo de autorización de los representantes, y por otra, también es mecanismo de exigencia de responsabilidad para los mismos, pues los electores no volverán a elegir a aquellos representantes que no actúan conforme a sus expectativas (Garcia, 2005), lo que convierte al sufragio en un mecanismo de control a posteriori (Garcia, 2001).

${ }^{10}$ Del inglés responsiveness, que en términos de la representación política significa que los representantes deben ser receptivos a los intereses de quienes representan (Pitkin, 1967).

${ }^{11}$ Del inglés accountability, que en términos de la representación política significa que los representantes deben responder a los representados por sus actuaciones (Pitkin, 1967). 
Ambos principios y el elemento de la rendición de cuentas se encuentran mediados de manera implícita por el concepto de transparencia que, aplicado a la actuación de los representantes, permite un constante monitoreo de la actividad y el proceso representativo (Godoy, 1998). En ese sentido, la transparencia alimenta no sólo la eficacia del proceso de deliberación, si no que hace posible que los ciudadanos puedan emitir una opinión informada, lo que permitiría afirmar que la representación política es verdaderamente democrática.

Para analizar el déficit democrático en la UE, los elementos de la democracia representativa son esenciales, pues sobre ésta se fundamenta la legitimidad de la legislación al interior de la UE, ya que en su proceso de formación intervienen las dos únicas instituciones que poseen un carácter representativo: el Consejo y el Parlamento Europeo. Adicionalmente, el estudio de los elementos principales de la democracia representativa como son la responsabilidad, la rendición de cuentas y la transparencia, permiten analizar cómo podría configurarse un déficit democrático en el mismo proceso de aprobación legislativa al interior de la UE.

\section{El déficit democrático en la Unión Europea: una definición problemática}

Desde sus inicios la UE no planteó mayores cuestionamientos a propósito de la naturaleza misma del proyecto de integración y por ello, éste mismo no representaba ningún desafío en términos de legitimidad democrática. Como afirma Katz, "la UE surge desde sus comienzos como un proyecto de elite basado en lo que se denomina consenso permisivo" (2001, p. 57). ${ }^{12}$ De esta manera no hay una real preocupación con relación al sustento democrático, pues la permisividad de la opinión pública se sustenta en considerar que la legitimidad democrática del proyecto descansa en manos de los gobiernos nacionales.

No obstante, tras la renovada actividad en la profundización de la integración europea durante las décadas de los ochenta y noventa, particularmente a partir de la firma y ratificación del Acta Única Europea en 1986 y posteriormente del Tratado de Maastricht en 1992, se hacen evidentes los cambios esenciales en el proceso de integración, donde la dimensión económica, aunque sigue direccionando el proceso, no es ya la única, pues poco a poco se va vislumbrando una profundización en la dimensión política de la integración europea a través del traslado de mayores competencias a nivel supranacional y el fortalecimiento de las instituciones supranacionales. Debido a esta serie de cambios en

\footnotetext{
${ }^{12}$ Este consenso permisivo se sustenta en cuatro supuestos: primero, que el proyecto europeo no iba a tener mayor impacto directo sobre la vida de la gente y dado sus carácter técnico era mejor dejar su diseño en manos de los tecnócratas, segundo, la creencia fundamentada de que la integración económica era necesaria para lograr una mayor competitividad en el mercado cada vez más globalizado; tercero, que en virtud de los Tratados y del mismo Acuerdo de Luxemburgo, la toma de decisiones siempre se daría por el consentimiento unánime de los gobiernos de los estados miembros, y finalmente, que el proceso de integración podía proceder sin la participación de las personas o bien que sus representantes parlamentarios siempre iban a ser consultados (Katz, 2001).
} 
los que cada vez es más profundo el impacto de la integración europea en la vida de los ciudadanos europeos y al hecho de que los mecanismos clásicos de control democrático que operan al interior de los Estados ya no son suficientes para garantizar la democracia al interior de la UE, surgen los cuestionamientos sobre la legitimidad democrática del proceso de integración europeo con el llamado déficit democrático.

El abordaje del tema del déficit democrático en la UE plantea de entrada una dificultad y es que no existe consenso sobre su definición, lo que se debe en gran medida a que hoy en día no hay claridad sobre qué es exactamente la UE. Su carácter sui generis impide encuadrarla en categorizaciones clásicas tanto del derecho internacional como de las relaciones internacionales (Kaelble, 2005). Adicionalmente, tampoco existe claridad respecto al concepto mismo de democracia aplicable al contexto de la UE ya que coexisten visiones opuestas (Warleigh, 2003). Así que estos hechos determinarán, en gran medida, las distintas posiciones frente al déficit democrático en la UE.

\section{El punto de partida: la "versión estándar"}

El tema del déficit democrático empieza a acaparar la atención hacia finales de los años ochenta, cuando la doctrina especializada en los temas europeos comienza a indagar sobre la naturaleza misma de este fenómeno, sus causas y las posibles vías para solucionarlo. Es así como a mediados de los años noventa surge la denominada "versión estándar" del déficit democrático en la UE, en la que se hace un intento por recoger los argumentos expuestos por analistas, políticos, medios de comunicación y la opinión pública en general que apuntan hacia una crítica de la democracia en la Unión Europea (Weiler, Haltern y Mayer, 1995). Esta "versión estándar" es retomada a finales de los años noventa por Simon Hix (Hix y Høyland, 2012), quienes sistematizan y amplían esta serie de argumentos en cinco áreas, cada una con un conjunto de afirmaciones que se recogen a continuación. En primer lugar, se destaca el mayor empoderamiento del ejecutivo en detrimento del control que pueden ejercer los parlamentos nacionales. Ya que las decisiones en la Unión Europea son tomadas principalmente por el Consejo y la Comisión Europea, los alcances en cuanto al control que pueden ejercer los parlamentos nacionales son insignificantes (Bonde, 2011) y esto se debe a que, por una parte, los gobiernos a través del Consejo pueden ignorar a los parlamentos cuando toman decisiones en Bruselas (Katz, 2001), y por otra, el sistema de votación que utiliza el Consejo, que al ser por mayoría cualificada aquellos que conformen la minoría deberán acatar la decisión así no estén de acuerdo; y finalmente, porque los parlamentos nacionales no ejercen ningún tipo de control sobre la Comisión Europea (Hix y Høyland, 2012).

Sobre este elemento, Robert Dahl da una mirada más amplia al establecer que el déficit democrático que experimenta la UE hace alusión al "costo de sumergir las democracias y los gobiernos nacionales en un más amplio y menos democrático sistema 
transnacional" (1994, p. 23). En ese sentido se plantea un dilema: escoger entre la capacidad de control democrático de los ciudadanos sobre las decisiones políticas o la capacidad del sistema para responder a las preferencias colectivas de los ciudadanos (1994). Esta disyuntiva es el resultado de lo que Dahl caracteriza como la tercera y actual transformación democrática, ${ }^{13}$ la cual surge como consecuencia de la reducción de la capacidad de los Estados nación frente a las fuerzas transnacionales.

El principal reto que plantea la adaptación de la democracia frente a esta tercera transformación es que se requeriría una gran delegación de poder hacia funcionarios que no son elegidos pero que hasta cierto punto dependen de quienes sí lo son. En virtud de esto, Dahl sugiere el fortalecimiento de las instituciones democráticas a nivel nacional ya que con ello se permite ejercer control democrático a los tomadores de decisiones transnacionales a través de la autoridad que delega, "previniendo así que la delegación se convierta en un efecto total y permanente de enajenación de control" (1994, p. 33).

En segundo lugar, se hace hincapié en la debilidad del Parlamento Europeo cuyos poderes no compensan la pérdida de los mismos en relación a los parlamentos nacionales (Warleigh, 2003); esto se debe, por una parte, al predominio del Consejo en relación al Parlamento Europeo en el proceso de aprobación legislativa y del presupuesto comunitario (Crum, 2005; Kaelble, 2005; Campbell, 2009), y por otra, la relación entre los ciudadanos y los eurodiputados no goza de misma afinidad que contiene la relación con los parlamentarios estatales (Hix y Høyland, 2012, p. 133).

En tercer lugar, no existen elecciones europeas ya que los ciudadanos no pueden ejercer su derecho al voto sobre políticas de la UE, salvo los referendos sobre reforma de los tratados o adhesión a la UE. Asimismo, en las elecciones de carácter nacional no se tratan temas europeos y lo mismo ocurre en las elecciones al Parlamento Europeo, pues tanto políticos como medios de comunicación nacionales abordan el tema cómo exámenes sobre las actuaciones del gobierno y los partidos nacionales (Hix y Høyland, 2012).

En cuarto lugar, se considera a la Unión Europea demasiado distante del ciudadano común, esto significa no sólo el escaso entendimiento que hay entre la población europea con relación al funcionamiento mismo de la UE (Kaelble, 2005), sino también la poca claridad en relación al nombramiento de la Comisión Europea la cual debería ser elegida directamente por los ciudadanos o, en su defecto, por el Parlamento Europeo (Crum, 2005). A lo anterior hay que sumarle, como también expresa Milev

\footnotetext{
${ }^{13}$ Robert Dahl (1994), describe tres transformaciones democráticas: la primera, da origen a las ciudades-Estado y se caracteriza por la participación democrática de manera directa; la segunda, es la que da origen a los Estados-nación por la escasa funcionalidad de las ciudades-Estado y se caracteriza por el surgimiento de la democracia representativa; y finalmente, la tercera transformación caracterizada por la reducción de las capacidades de los Estados-nación fruto de las fuerzas transnacionales y respecto a la cual una serie de retos a la concepción misma de democracia.
} 
(2004), el hecho de que el proceso político de la UE está dominado por un carácter tecnocrático, lo que impide que actores y ciudadanos identifiquen claramente las preferencias políticas (Hix y Høyland, 2012).

$\mathrm{Al}$ respecto también se puede anotar que, por una parte, el proceso legislativo al interior de la UE es bastante reservado, cuestión que impide la correcta información por parte de los ciudadanos; y por otra, el hecho de que existe un excesivo ejercicio de la delegación, lo que genera una falta de responsabilidad democrática en el proceso (Crombez, 2003).

Finalmente, en quinto lugar, como resultado de la convergencia de todos los factores antes mencionados, está lo que Hix y Høyland (2012) denominan como deriva política, y es el escaso apoyo que reciben las políticas aprobadas en la UE por parte de la mayoría de los ciudadanos e incluso de varios Estados miembros. Sobre este particular, Fritz Scharpf argumenta que la legitimidad democrática y por ende el apoyo de la ciudadanía a las decisiones políticas aumenta en la medida que estas sean producto de una elección colectiva autentica y eficaz, pero si estas decisiones proceden de autoridades a las que no se les puede exigir responsabilidades políticas, tanto la legitimidad democrática como el apoyo ciudadanía disminuyen (1999).

\section{Posiciones contrarias al déficit democrático}

Otros autores, por su parte, consideran desacertada la afirmación de que realmente exista un déficit democrático en la UE y sugieren que ello se debe a una concepción idealista de lo que realmente la UE y lo que se puede esperar de ella. En ese sentido encontramos los argumentos planteados de manera particular por Andrew Moravcsik (2002) y Giandomenico Majone (1998).

Moravcsik argumenta que si se consideran los criterios razonables para juzgar qué tan democrático es un gobierno las críticas sobre la legitimidad democrática de la UE carecerían de fundamento, y afirma que "los controles constitucionales, los controles democráticos indirectos a través de los gobiernos nacionales y los poderes cada vez mayores del PE son suficientes para asegurar que la política al interior de la UE es, en casi todos los casos, transparente, eficaz y políticamente sensible a las demandas de los ciudadanos europeos" (p. 605).

Con relación a la crítica que se hace sobre los altos niveles de delegación, Moravcsik apunta que al interior de los Estados estos niveles de delegación también se dan a través de una serie de organismos reguladores y que se trata de una práctica extendida en las democracias modernas, justificada en términos pragmáticos y sustentada en una extensa normatividad. Además, lo que al respecto ocurre en la UE y que la mayoría de los críticos observan como un aislamiento de la misma, no es otra cosa que la manifestación de la división de trabajo producto de una relación simbiótica entre la UE y los gobiernos nacionales en la que serán estos últimos los garantes de inducir a la participación popular. 
De igual forma, afirma que la UE cuenta con mecanismos suficientes de participación y responsabilidad democrática que se manifiestan de dos maneras: por una parte, el mayor fortalecimiento en las competencias del Parlamento Europeo, el cual es elegido de manera directa por los ciudadanos de la UE, y por otra, los gobiernos democráticamente electos en los Estados miembros quienes dominan los procesos de decisión al interior de las estructura intergubernamental de la UE.

Finalmente, respecto al tema de ampliar la participación de los ciudadanos al interior de las instituciones políticas europeas, Moravcsik apunta a que esta afirmación no tiene ninguna relevancia y que hacerlo no sería aconsejable ya que "la actividad legislativa y reglamentaria de la UE está inversamente correlacionado con la relevancia de los asuntos en la mente de los votantes europeos, así que hacerlo no va a superar la apatía de los ciudadanos al respecto" (p. 615). Los temas sobre los cuales los ciudadanos tienen mayor interés, como por ejemplo la salud, educación, seguridad social, entre otros, siguen siendo temas que se abordan directamente al interior de los Estados, mientras que los temas que se trabajan al interior de la UE, como es el caso de la liberación comercial, los temas arancelarios y la coordinación de la política exterior, son los que revisten menor interés para los ciudadanos; así pues, el problema no radica en los espacios de participación sino en la relevancia que otorgan los ciudadanos respecto a los asuntos sobre los cuales la UE tiene competencia.

Desde otra perspectiva, Majone sostiene que una de las causas que permiten percibir lo que se ha denominado como déficit democrático en la UE es la idea errónea de equiparar la naturaleza y funcionamiento de las instituciones comunitarias con aquellas que se supondrían "equivalentes" en plano nacional, cuando es claro que la UE posee una arquitectura institucional sui generis, diseñada por los Tratados y debidamente ratificada por los parlamentos nacionales bajo el cual el reparto de competencias es claramente definido y limitado. Entonces, el problema radica en la naturaleza y funcionamiento de las instituciones no mayoritarias al interior de la UE como es el caso de la Comisión Europea.

De esta manera, entendiendo a la UE como un proceso de integración económico, ${ }^{14}$ las políticas derivadas de las competencias que se le han asignado son de carácter regulador, lo que significa que de estas no se puede esperar una condición redistributiva o de asignación de valores, sino que se espera de ellas acciones coordinadas que hagan frente a los fallos del mercado produciendo efectos políticos pareto-eficientes (Follesdal y Hix, 2005). ${ }^{15} \mathrm{Si}$ estas políticas se derivaran de competencias otorgadas a instituciones mayoritarias, la eficiencia del

\footnotetext{
${ }^{14}$ Majone crítica la posición que sugiere que el proceso de integración económico de la UE debe estar seguido por un proceso de integración político. En ese sentido afirma que "la 'despolitización' de la política europea es el costo que debe pagar para preservar la integridad de la soberanía estatal" (1998, p. 5).

${ }^{15}$ Follesdal y Hix definen un efecto pareto-eficiente como "aquel en el que el reporte de algún beneficio para un sector o actor no reporta una peor situación para los demás" (2005, p. 7).
} 
proceso de toma de decisiones estaría gravemente comprometida ya que no habría garantía de continuidad. Por esta razón, Majone expone que la delegación es la herramienta adecuada que permite solucionar problemas de acción colectiva entre los Estados miembros de la UE.

Así bien, para Majone es una equivocación suponer que la UE adolece de un déficit democrático por el hecho de que las decisiones políticas en la UE sean tomadas por órganos de carácter no mayoritario como lo es la Comisión Europea, ya que ésta actúa tras un proceso de delegación por parte de los Estados miembros, lo que le otorga una legitimidad democrática ex ante. Lo que sí es una dificultad, afirma, es que existe un problema de credibilidad originado en la poca claridad en los procedimientos de toma de decisiones, lo que podría solventarse mediante la introducción de mecanismos que otorgaran una mayor transparencia en estos procesos y que fortalecieran la revisión y debate posterior, por parte de diferentes agentes sobre las políticas comunitarias (Follesdal y Hix, 2005).

\section{Otras visiones sobre el déficit democrático}

Desde la sociología, autores como Ulrich Beck, Edgar Grande y Jürgen Habermas han expuesto sus apreciaciones sobre el déficit democrático en la UE. Estos autores coinciden en que es necesario repensar el modelo actual de la UE el cual falla en su estructura al encontrarse supeditado a categorías tradicionales.

Beck y Grande (2006), sugieren que las principales críticas que se le hacen hoy en día a la UE en relación a su legitimidad democrática, parten de supuestos incorrectos que terminan invalidando las conclusiones a las que se llegue. Una de ellas es lo que denominan como ilusión nacional, según la cual se espera que el proceso de democratización de la UE esté basado en los principios de democratización de los Estados. En este caso existe una absolutización del modelo nacional de democracia producto de un anhelo nostálgico de la soberanía nacional que desconoce la naturaleza de la UE, la cual, si bien está conformada por Estados democráticos, en sí misma no es un Estado -según el concepto tradicional-, sino que pertenece a un "orden categorial distinto" (p. 44). De ahí que la pregunta esencial no es cómo aplicar los estándares democráticos propios de los Estados, ya que se terminan promoviendo un retroceso en el proceso de europeización, ${ }^{16}$ sino, entendiendo la particularidad de la UE, qué modelos democráticos pueden desarrollarse para legitimarla democráticamente.

Otro supuesto incorrecto es lo que Becky Grande denominan como ilusión tecnocrática, que aunque no se opone al proceso de europeización sí lo deslegitimiza democráticamente. Aunque demuestra una apuesta positiva hacia la integración, ve este proceso como un fin en sí mismo pero no como un medio, lo que resulta problemático pues se procura mantener la

\footnotetext{
${ }^{16}$ El concepto de europeización es entendido como "un proceso institucionalizado de permanente
} transformación" (Beck y Grande, 2006, p. 23). 
integración a través de soluciones de carácter técnico que no cuentan con la participación democrática de los ciudadanos europeos; de ahí que se pueda hablar de un doble déficit de legitimación democrática. Por una parte, los ciudadanos europeos no tienen una amplia participación en el proceso de toma de decisiones al interior de la UE pues sólo lo hacen a través de las elecciones del Parlamento Europeo cuyas capacidades son reducidas frente a otros órganos supranacionales; y por otra parte, al no existir suficiente participación por parte de los ciudadanos en la toma de decisiones, se compromete la eficacia en las políticas europeas ya que en su mayoría están supeditadas a los intereses nacionales.

Para estos autores es necesario romper con la "falsa autoconcepción nacional" que domina a Europa y que se refleja en la dicotomía entre una integración profunda o el reforzamiento de los Estados nacionales que la componen. Para lograr esto, se propone la idea de la Europa cosmopolita como una nueva forma de sociedad y de política fundamentada en el reconocimiento de las diferencias, el fortalecimiento de la sociedad civil europea y la incorporación de modelos posnacionales de democracia.

Por su parte, Jürgen Habermas en La inclusión del otro (2010), comparte los supuestos básicos que permiten identificar el denominado déficit democrático en la UE. Por un lado, afirma que "los órganos de la Comunidad crean derecho europeo que vincula a los Estados miembros, la UE ejercita, por tanto, unos derechos soberanos que hasta entonces en sentido propio se reservaban el Estado [...] mientras el Parlamento Europeo disponga sólo de débiles competencias, a estas resoluciones les faltará una legitimación democrática directa" (p. 137). Por otro, señala que "los órganos ejecutivos de la Comunidad derivan su legitimación de la de los gobiernos de los Estados miembros. No son órganos de un Estado que haya sido constituido mediante un acto de voluntad de todos los ciudadanos europeos unidos" (p. 137). De esta manera, el déficit democrático en la UE es entendido como la tendencia intergubernamental y burocrática que domina el proceso de toma de decisiones al interior de la UE y que carece de una legitimidad democrática directa (Habermas, 2009).

\section{Las competencias legislativas en la Unión Europea}

A diferencia de lo que tradicionalmente se observa al interior de los Estados, donde la competencia legislativa reside exclusivamente en las instituciones parlamentarias, en la UE esta competencia no está en manos de una sola institución sino en tres: la Comisión, con el poder de iniciativa legislativa, el Consejo, como el órgano supremo de decisión, y el Parlamento, quien de manera conjunta con el Consejo actúa como colegislador en el procedimiento legislativo ordinario.

\section{El rol del Parlamento Europeo en las competencias legislativas}

La figura institucional del PE al interior de la UE reviste un especial interés, no sólo por el hecho mismo de incluir un institución de carácter parlamentario en el seno de una organización internacional, como se declara formalmente la UE, sino por el incremento 
sustancial de competencias del que ha sido objeto y cuya evolución da cuenta de los intentos en profundizar la dimensión política del proceso de integración europeo.

Siguiendo las afirmaciones de Corbett, Jacobs y Shackleton, "el establecimiento desde un comienzo de un cuerpo parlamentario entre las instituciones comunitarias, no sólo es un gesto hacia un escrutinio democrático de los poderes legislativos supranacionales, sino que también simboliza la aspiración de la Comunidad a desarrollarse de manera cercana a una federación" (1995, p. 8).

Los antecedentes del PE se remontan a la Asamblea Parlamentaria ${ }^{17}$ establecida por el Tratado de la Comunidad Europea del Carbón y el Acero (TCECA) en el año 1951. Su inclusión dentro de la estructura comunitaria obedece a dos razones fundamentales: la impronta federal que atraviesa el diseño de las primeras Comunidades, que hace indispensable la participación de representantes investidos por el libre sufragio y detentadores de poderes delegados por la voluntad popular, y la necesidad de controlar a la Alta Autoridad (posterior Comisión) para que, como órgano independiente de los Estados, no degenerara en una tecnocracia sin control (Manzanares y Quentin, 1984, p. 34).

Posteriormente, con la entrada en vigor del Tratado de la Comunidad Económica Europea (TCEE) y el Tratado de la Comunidad Europea de Energía Atómica (TCEEA) en 1958, se introduce la consulta como el primer procedimiento legislativo en el que el PE tiene participación. Para este momento, como afirman Corbett, Jacobs y Shackleton (1995), los gobiernos de los Estados miembros habían sido muy cuidadosos en no transferir mayores poderes al PE, incluso aún en aquellas áreas en las que sus propios parlamentos nacionales habían cedido responsabilidad a favor de las instituciones comunitarias. Por esta razón, la opinión que diese el PE en el marco de éste procedimiento no tenía ningún tipo de obligatoriedad para el Consejo.

A pesar de contemplarse en el TCECA y de haberse dado la indicación en los TCEE y TCEEA, ${ }^{18}$ sólo hasta 1979 el PE fue electo por sufragio universal, hecho que simboliza el compromiso europeo con los valores de la democracia representativa. ${ }^{19}$ A partir de las elecciones directas, el PE fue poco a poco empoderándose de su rol al interior del proceso legislativo en la UE. A pesar de que hasta ahora su participación estaba restringida al procedimiento de consulta, esta institución, a través de una importante reforma

\footnotetext{
${ }^{17}$ El 30 de marzo de 1962 esta institución, a pesar de las críticas, mediante una Resolución se autodenomina "Parlamento Europeo". Nombre que se hará oficial con la firma del AUE de 1986 (Corbett, Jacobs y Shackleton, 1995).

${ }^{18} \mathrm{Si}$ bien la indicación para la elección por sufragio directo estaba expuesta en los tratados constitutivos, la razón por la cual sólo hasta el año de 1979 se hace efectiva pone de manifiesto la extrema precaución que tenían los Estados miembros de no empoderar demasiado las instituciones comunitarias, particularmente el Parlamento Europeo.

${ }_{19}$ TUE, Título Segundo: Disposiciones sobre los principios democráticos.
} 
en su Reglamento Interno, incorpora mecanismos de presión sobre la Comisión para que sus opiniones al interior de éste procedimiento no sean ignoradas (Navarro, 1995).

De acuerdo con Morata (1999), el PE experimentó un salto cualitativo sustancial a partir de la entrada en vigor del AUE, pues gracias a éste la institución queda directamente implicada en el proceso de toma de decisiones al interior de la UE a través del procedimiento de cooperación, procedimiento que posteriormente se verá transformado en el procedimiento de codecisión mediante el TUE.

En los 61 años de existencia de los que hoy es Parlamento Europeo se puede apreciar un esfuerzo por dotarlo de mayores capacidades al interior de la UE. Sin embargo, este esfuerzo se ve contrarrestado por el complicado diseño del proceso legislativo al interior de la UE, bajo el cual los poderes del PE siguen siendo de carácter negativo.

\section{Los procedimientos legislativos en la Unión Europea}

El TFUE en su Capítulo Segundo reorganiza los procedimientos legislativos al interior de la UE, distinguiendo el procedimiento legislativo ordinario (anterior procedimiento de codecisión) como el más importante mecanismo de producción normativa al interior de la UE, frente a los demás procedimientos que subsisten y que ahora se denominan procedimientos legislativos especiales..$^{20}$

Estos últimos se dividen en dos tipos de procedimientos. Por una parte, el procedimiento de consulta, incorporado en el TCEE (art. 137) y el TCEEA (art. 107), no se trata de un poder legislativo en estricto sentido, sino en un mecanismo que le permite al PE ejercer cierta influencia indirecta en el proceso de aprobación legislativa. Este mecanismo, que en principio no es de carácter general pues sólo aplica en aquellos casos en que los Tratados lo prevean, se desarrolla mediante el mandato que impone estos Tratados al Consejo de solicitar y conocer la posición del Parlamento frente a la iniciativa presentada por la Comisión sobre un tema en particular antes de tomar una decisión, así el resultado de este dictamen no sea vinculante para esta institución (Mangas y Liñán, 2006; Navarro, 1995). Por otra parte está el procedimiento de conformidad que consiste en una opinión política del PE de carácter vinculante sobre temas fundamentales y de interés común. Introducido por el TCECA, en principio sólo aplicaba para asuntos correspondientes a la actuación internacional de la Comunidad como los tratados de adhesión de nuevos Estados miembros y los acuerdos internacionales de asociación. Posteriormente, el AUE y el TUE extienden las áreas en las que se aplica el procedimiento de conformidad, como por ejemplo: acuerdos de cooperación con terceros países; acuerdos que tengan implicaciones presupuestarias importantes para la Comunidad; sanciones a un Estado miembro en caso de violación de derechos fundamentales; en los casos que se requiera emprender una cooperación reforzada en materias que deben ser

\footnotetext{
${ }^{20}$ TFUE, Capítulo 2: Actos jurídicos de la Unión, procedimientos de adopción y otras disposiciones.
} 
aprobadas por codecisión; con relación a la Unión Económica y Monetaria al encomendar tareas específicas al Banco Central Europeo en lo que concierne a la supervisión de las entidades financieras; la modificación de determinadas disposiciones del Estatuto del Sistema Europeo de Bancos Centrales; en lo concerniente a los Fondos Estructurales y el establecimiento de Fondos de Cohesión y finalmente, en lo relativo al procedimiento electoral uniforme (Mangas y Liñán, 2006).

\section{Procedimiento legislativo ordinario}

La incorporación de este procedimiento es el avance más significativo relacionado a la participación del PE en el proceso de aprobación legislativa en la UE. Incorporado por el TUE (art. 189 B) y elevado a la categoría de procedimiento legislativo ordinario en el Tratado de Lisboa (art. 289), pretende dar cierta paridad al PE frente al Consejo en el proceso de aprobación legislativa como si se tratara de un sistema bicameral.

Este procedimiento se desarrolla mediante un sistema de doble lectura al igual que el procedimiento de cooperación, pero que en este caso la propuesta de la Comisión es enviada de manera simultánea tanto al PE como al Consejo para que cada uno siente su posición sobre el texto en la primera lectura. El primero en pronunciarse al respecto es el PE, quien remite su posición al Consejo para que éste lo apruebe. En esta etapa puede pasar una de tres cosas: que el Consejo apruebe el texto enviado por PE, caso en el cual el Consejo adoptará de manera definitiva la decisión; o puede rechazar la posición del PE, caso en el que el Consejo le remitirá a éste su posición para que sea estudiada por el PE quien podrá aceptar la posición del Consejo de manera expresa o tácita dando lugar a la adopción definitiva de la decisión; o podrá rechazarlo durante la segunda lectura y en este caso no se adoptará la decisión.

\section{GRÁFICA 1 ALTERNATIVA DE APROBACIÓN}

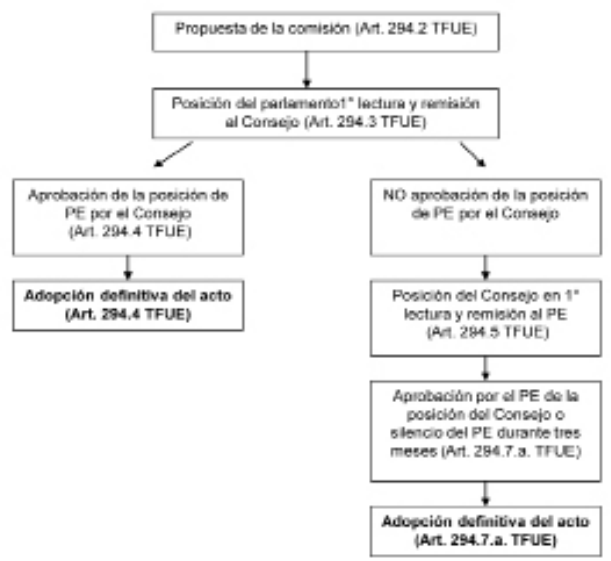

Fuente: Díez-Moreno (2006, p. 190), con modificaciones de la autora. 
Cuando en el procedimiento legislativo ordinario el PE establece enmiendas a los textos, lo que ocurre durante la segunda lectura, iniciada cuando el Consejo remite su posición al $\mathrm{PE}$, dichas enmiendas son enviadas al Consejo, quien podrá aceptarlas y con ello adoptar la decisión, o rechazarlas, caso en el cual se convocará al Comité de Conciliación. Este comité, que se reúne a solicitud del Consejo, está diseñado dentro del mismo procedimiento para procurar un espacio de reflexión a propósito del texto que ha sido de difícil adopción. Su composición es de carácter paritario en términos matemáticos ya que en él se reúnen todos los miembros del Consejo o un número de representantes y un número igual de representantes del PE. Igualmente, la Comisión participa al interior del Comité, pero sólo como facilitadora de un acercamiento entre las posiciones de las partes.

\section{GRÁFICA 2 ALTERNATIVA DE ENMIENDAS}

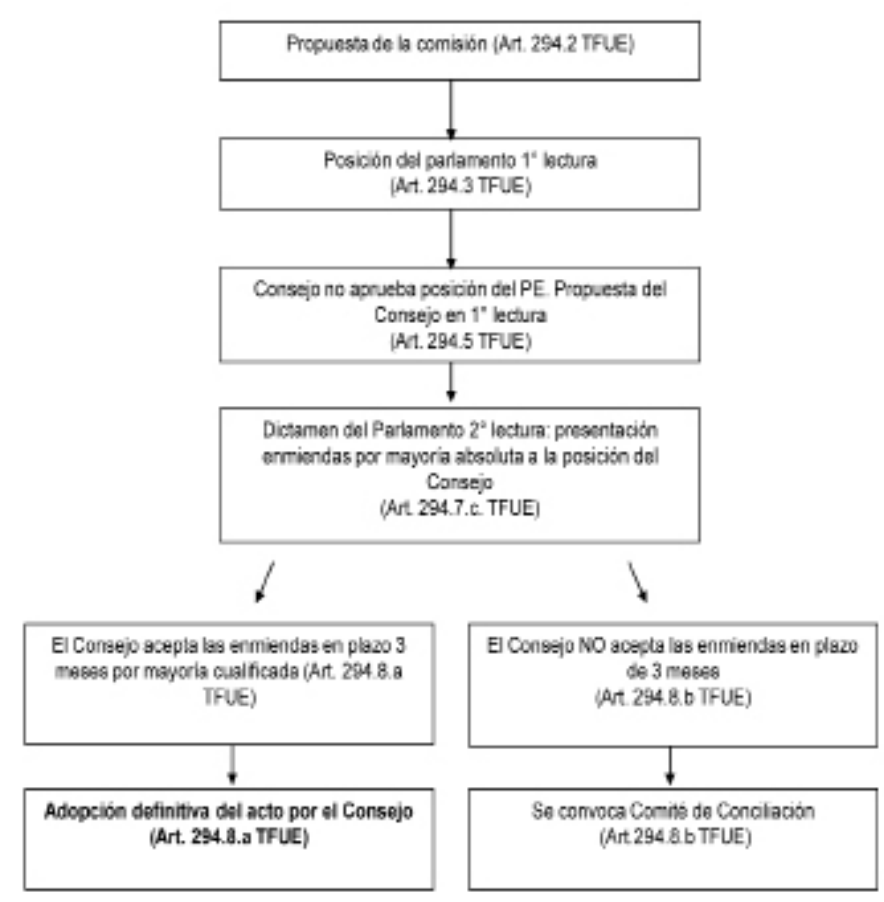

Fuente: Díez-Moreno (2006, p. 191), con modificaciones de la autora.

$\mathrm{Al}$ interior del Comité de Conciliación puede pasar que definitivamente no se llegue a un acuerdo por parte de los miembros o representantes del Consejo y los representantes del PE, caso en el cual la decisión no será adoptada; pero también es posible que el Consejo decida adoptar el acto por unanimidad incorporando las enmiendas del PE, si el PE no veta éste acto, la decisión es aprobada (Navarro, 1995). Pero si se logra un 
acuerdo entre los miembros o representantes del Consejo y los representantes del PE, se adoptará un texto conjunto que deberá ser votado mediante una tercera lectura, tanto en los plenos del PE como del Consejo. Si el PE y el Consejo, cada uno en sus plenarias, aprueban el texto, la decisión quedará finalmente adoptada, pero si el Consejo no acepta el texto procedente del Comité de Conciliación, la decisión quedará plenamente rechazada.

\section{GRÁFICA 3 COMITÉ DE CONCILIACIÓN}

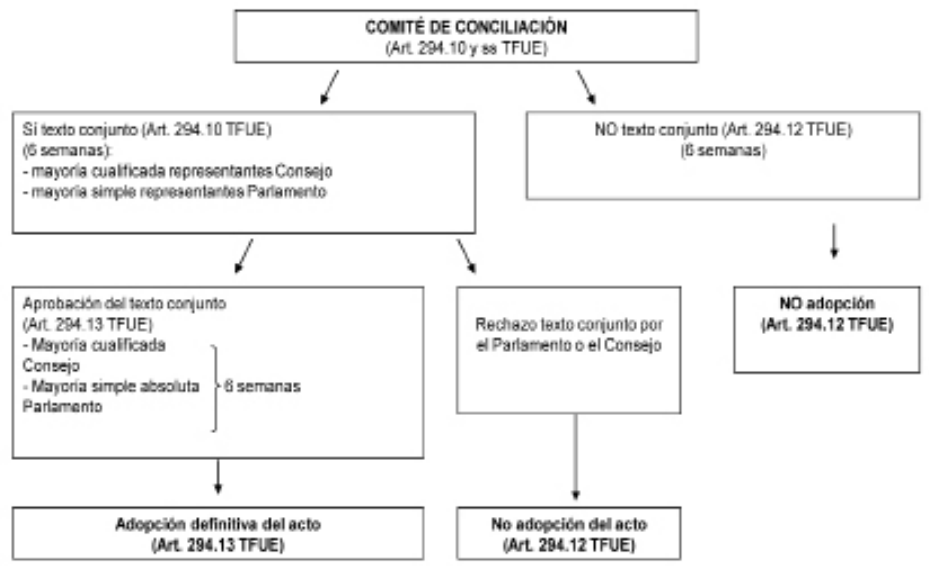

Fuente: Díez-Moreno (2006, p. 191), con modificaciones de la autora.

\section{GRÁFICA 4 ALTERNATIVA DE RECHAZO PLENO}

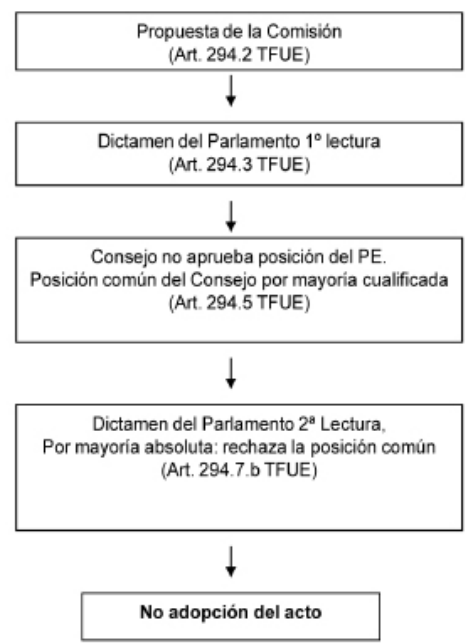

Fuente: Díez-Moreno (2006, p. 192), con modificaciones de la autora. 
Como se puede apreciar en este procedimiento, el papel que juega la Comisión no es tan activo como en los anteriores, ya que aquí su rol de intermediario entre el PE y el Consejo queda relegado pues se estipula el acercamiento y las negociaciones directas entre ambas instituciones. Además, cabe destacar que el texto que se adopte en el Comité de Conciliación -en virtud de esas negociaciones directas entre el Consejo y el PE-, puede diferir del texto inicialmente propuesto por la Comisión, lo que supone un quiebre en el equilibrio institucional (Mangas y Liñán, 2006). De igual manera aunque resalta que la participación del PE en el proceso es mucho más activa que en los anteriores procedimientos, no se puede decir que dicha participación sea de carácter positivo ya que el mecanismo por el cual el PE puede incidir en el proceso legislativo es a través del poder de veto.

Finalmente, otro elemento importante es que no hay claridad respecto a los criterios orientadores que permiten establecer qué temas serán objeto de trámite mediante el procedimiento legislativo ordinario (Navarro, 1995).

\section{La cara oculta del Proceso Legislativo Ordinario en la UE}

Tras la incorporación en el TUE del procedimiento legislativo ordinario, las tensiones entre el Consejo y el PE no se hicieron esperar. El predominio hasta ahora del Consejo como principal órgano decisor al interior de la UE, se ve retado por el posicionamiento del PE como colegislador en el desarrollo del proceso legislativo.

Los permanentes retrasos e incluso bloqueos impuestos por el PE con el propósito de hacer valer su nuevo peso en el procedimiento legislativo, hace que el Consejo se vea obligado a aceptar que el PE tenga un rol más activo al interior del mismo. Este hecho permite que durante los años 1994 y 1995, la Comisión, el Consejo y el PE crearan un sistema de reuniones informales para negociar compromisos sobre temas controversiales al interior del proceso legislativo (Shackleton, citado en Farrell y Héritier, 2003, p. 21). Estas reuniones, que empezaron a conocerse como "dialogo tripartito", ${ }^{21}$ en un comienzo sólo se convocaban tras la segunda lectura al interior del proceso legislativo ordinario. Tal fue su eficacia para lograr acuerdos que prontamente se incorporaron para evitar de manera sistemática el tener que llegar al Comité de Conciliación. También, y por esta misma razón, este tipo de reuniones se empiezan a desarrollar antes de la primera lectura en el procedimiento legislativo ordinario, con el objeto de crear "acuerdos tempranos" que permitan aprobar la legislación en esta primera lectura (Farrell y Héritier, 2003).

Posteriormente el Tratado de Ámsterdam, además de ampliar los temas que serán objeto de decisión mediante el procedimiento legislativo ordinario (anterior procedimiento

\footnotetext{
${ }^{21}$ En este diálogo tripartito participan: delegados de la Comisión, los vicepresidentes del PE, los representantes de la Presidencia del Consejo, los presidentes de la comisión, los parlamentarios proponentes y los representantes del grupo de trabajo en el Consejo (Farrell y Héritier, 2003).
} 
de codecisión), también -y esto con el objeto de hacer más eficaz el procedimiento- da vía libre a la práctica de los "acuerdos tempranos" logrados mediante los diálogos tripartitos (Farrell y Héritier, 2003; Héritier y Reh, 2011; Reh et al., 2010). Aunque en principio el Tratado de Ámsterdam aprueba estos "acuerdos tempranos" para asuntos de carácter técnico, después se ampliaron para temas que fuesen de carácter urgente ( $\mathrm{Fa}$ rrell y Héritier, 2003). De igual manera, es oportuno mencionar que estos acuerdos se encuentran estipulados y supuestamente regulados en las declaraciones conjuntas del PE y el Consejo, relativas a las prácticas en el procedimiento legislativo ordinario. ${ }^{22}$

Un examen de la legislación promulgada por la UE través del procedimiento legislativo ordinario revela que desde la introducción de los "acuerdos tempranos", en 1999, la legislación europea aprobada por esta vía rápida ascendió al 72\% durante la legislatura 2004-2009 (Reh et al., 2010). Este dato es especialmente revelador, el 72\% de la legislación al interior de la UE se ha aprobado mediante reuniones de carácter informal entre un grupo restringido y además aislado de representantes del PE, el Consejo y la Comisión. Si bien estos acuerdos alcanzados mediante los "diálogos tripartitos" aumentan la eficacia del proceso legislativo ordinario, el desarrollo de los mismos tiene una serie de implicaciones directas sobre el déficit democrático en la UE, pues no sólo atentan contra los principios de la democracia representativa en lo que se fundamenta la UE, sino que socavan los esfuerzos por fortalecer la institucionalidad y legitimidad del PE, dejando por el piso las reformas institucionales de los últimos veinte años.

\section{EI TFUE y el "refuerzo formal" de la democracia representativa en la UE}

Ante las demandas por una Europa más transparente, democrática y eficaz, el TFUE incorpora una serie de reformas que buscan - al menos formalmente- dar la impresión de haber dado un paso adelante en la profundización en materia democrática al interior de la UE, como se expondrá en el siguiente apartado.

\section{EI TFUE y el intento de fortalecer al PE en el proceso legislativo en la UE} Una primera disposición que introduce el TFUE en relación al fortalecimiento del PE en el proceso legislativo, es la clasificación que hace de los procedimientos legislativos al interior de la UE. El TFUE en su artículo 289 divide en dos los procedimientos

\footnotetext{
22 Ver Declaración común del Parlamento Europeo, el Consejo y la Comisión, de 13 de junio de 2007, sobre las modalidades prácticas del procedimiento de codecisión, Capítulo VI, artículo 70. Una revisión de este documento resalta que el lenguaje bajo el cual supuestamente se regula éste tipo de prácticas informales entraña más una condición de posibilidad que una condición de obligatoriedad, lo que en términos prácticos dificulta establecer si ciertamente el desarrollo de estas prácticas cumplen con los parámetros de transparencia y responsabilidad a los que hacen mención.
} 
existentes para la adopción de actos legislativos: el procedimiento legislativo ordinario y los procedimientos legislativos especiales.

Especial importancia reviste el procedimiento legislativo ordinario, definido en el artículo 294 del TFUE, no sólo porque reemplaza -al menos en términos nominales-al anterior procedimiento de codecisión, sino, porque además, extiende el número de bases jurídicas ${ }^{23}$ que empezarán a regirse mediante éste procedimiento. Esto significa que el PE ahora entra a hacer parte del proceso de toma de decisiones sobre más áreas comunitarias de las que tenía antes con el TUE y los tratados de Ámsterdam y Niza. ${ }^{24}$

En relación a los procedimientos legislativos especiales, aunque el TFUE no los define como sí lo hace con el procedimiento legislativo ordinario, se entiende que hace referencia al procedimiento de consulta y al procedimiento de conformidad. Respecto al ámbito de aplicabilidad de estos procedimientos, es claro que es mucho más reducido de lo que era antes de la entrada en vigor del TFUE, pues el procedimiento legislativo ordinario abarca hoy alrededor de 85 bases jurídicas (Martín y Pérez de Nanclares, 2010), dejando un margen muy estrecho y preciso para la aplicación de estos otros dos procedimientos.

Cabe resaltar que los criterios bajo los cuales se hace la asignación de las bases jurídicas para que ciertos temas sean sometidos a un proceso de decisión, mediante un procedimiento en particular, no son realmente claros. Por tomar un ejemplo, en relación a las temáticas propias del espacio de libertad, seguridad y justicia, para el caso específico de la cooperación policial no operativa (art. 87.2 TFUE), rige el procedimiento legislativo ordinario, mientras que en el caso de la cooperación policial operativa (art. 87.3 TFUE), rige el procedimiento legislativo especial de consulta. Utilizando la lógica, lo que se puede deducir de lo anterior es que, tratándose de temas sensibles en materia de seguridad, los Estados prefieren ejercer un dominio más directo del procedimiento por el cual se adoptan los actos legislativos sobre esa materia.

El ejemplo anterior resalta la tensión permanente que existe dentro de la UE en relación con el carácter federal e intergubernamental de la UE, tensión que como se expuso anteriormente, también se manifiesta en las dinámicas propias del procedimiento legislativo ordinario, pero también y de manera particular, en el desarrollo de los “acuerdos tempranos", como se expondrá más adelante.

\footnotetext{
${ }^{23}$ La definición de las bases jurídicas funciona en virtud del sistema de atribución de competencias en la UE (Navarro, 1995).

${ }^{24}$ Entre muchas otras áreas, mediante el proceso legislativo ordinario el PE entra en calidad de colegislador sobre temas como: controles de fronteras y visados, asilo, inmigración, integración de inmigrantes, cooperación judicial civil, cooperación judicial penal, armonización de tipos penales y sanciones, prevención de la delincuencia, evaluación de Eurojust, cooperación policial no operativa y regulación y control de Europol (Martín y Pérez de Nanclares, 2010).
} 
En relación al impacto de las prácticas informales, es importante resaltar que el TFUE no hace mención en ninguno de sus apartados respecto a los "diálogos tripartitos" ni a los “acuerdos tempranos", lo que supone claramente que este tipo de prácticas siguen existiendo y no tienen, por ahora, la posibilidad de ser reguladas de manera formal.

En ese sentido, a pesar de que el TFUE intenta dar una mayor visibilidad y un mayor empoderamiento al PE dentro del procedimiento legislativo ordinario con miras a reforzar la legitimidad de los actos legislativos de la UE, dicho intento, a la luz de los "acuerdos tempranos", resulta en vano por varias razones. En primer lugar, si tenemos en cuenta que la naturaleza del PE como institución comunitaria es la de ser el principal órgano de representación política al interior de la UE, ${ }^{25}$ las dinámicas de este tipo de prácticas informales contrarían la necesaria publicidad de los procesos de debate en los que se adoptan las decisiones, impidiendo que los ciudadanos europeos puedan acceder a la información necesaria que les permita formarse una opinión, y además, dificulta la identificación no sólo de los representantes, sino también de los intereses que están en juego, imposibilitando establecer responsabilidades y el ejercicio de mecanismos de rendición de cuentas. En segundo lugar, el análisis que sobre estas prácticas informales realizan Farrell y Héritier $(2003)^{26}$ muestra una tendencia creciente sobre el ejercicio de influencia por parte de los Estados sobre los eurodiputados de las delegaciones nacionales, con el objeto de manipular el proceso legislativo de una manera poco responsable y antidemocrática. En tercer lugar, y siguiendo con los análisis de Farrell y Héritier (2003), cuando los Estados miembros aún no ha llegado a una posición común dentro del Consejo, el país que ejerce la Presidencia de turno se encuentra en una posición de influencia única al interior del Consejo, pues al estar informado respecto a estas reuniones, puede hacer uso de esta información para afectar la percepción de los otros actores y así ejercer influencia en el proceso legislativo.

\section{El TFUE y el intento de dotar de mayor transparencia el proceso legislativo en la UE}

El TFUE, en su art. 15, establece conforme al principio de apertura que tanto las sesiones del PE como las del Consejo en las que se delibere y vote un proyecto de acto legislativo, serán de carácter público. De igual manera, otorga el mandato de garantizar la publicidad

${ }^{25}$ En virtud de su composición, mediante elecciones directas de los ciudadanos comunitarios.

${ }^{26}$ Es importante aclarar que los análisis realizados por Farrell y Héritier (2003), Reh, et. al. (2010) y Héritier y Reh (2011), sobre los "diálogos tripartitos" y los "acuerdos tempranos", se basan en investigaciones de índole cuantitativa, construidos a partir de los resultados de entrevistas con los actores implicados en estos procesos informales y de la revisión de las estadísticas sobre los porcentajes de aprobación legislativa en la UE, y cuyos resultados son examinados a través de los enfoques de elección racional e institucionalista. Teniendo presente que este estudio es de carácter cualitativo y eminentemente interpretativo, aquí se rescatan las principales conclusiones a las que se llegan dichas investigaciones para ser examinadas a la luz del problema de investigación que se ha planeado. 
de los documentos relativos a los procedimientos legislativos en la UE. El principio de apertura, ya se encontraba consagrado en el TUE (art. $1^{\circ}$ ), pero en el TFUE se busca darle un mayor impulso, especificando la manera como se garantizará.

El reforzamiento práctico de este principio a través del TFUE obedece a la necesidad de acercar a los ciudadanos europeos no sólo hacia el funcionamiento en general de la UE sino, específicamente, hacia el proceso de toma de decisiones para que en virtud de los principios de la democracia representativa los ciudadanos puedan tener acceso a la información, lo que les permitirá identificar los intereses en juego, establecer responsabilidades y ejercer mecanismos de rendición de cuentas. Sin embargo, si tenemos en cuenta que la mayor parte de la legislación tramitada en la UE mediante el procedimiento legislativo ordinario es adoptada mediante los "acuerdos tempranos" (Reh et. $a l$. 2010), queda claro que éstos, por su naturaleza informal, no cuentan con el carácter público al que hace referencia el TFUE, lo que significa que estos acuerdos impiden a los ciudadanos europeos tener un real acceso a la información.

Según las dinámicas de los “acuerdos tempranos", una vez se ha llegado a un acuerdo entre el PE y el Consejo, éste es tramitado como la posición del PE en su primera lectura, y una vez transmitido al Consejo, éste lo aceptará, quedando aprobado el acto legislativo (Reh et. al, 2010). De esta manera, no sólo se termina dotando de una legitimidad "formal" mas no de contenido real a las decisiones que se han tomado de manera informal y que se convertirán en actos legislativos, sino que además la información vital del proceso legislativo, que debería ser de libre acceso para los ciudadanos comunitarios, queda oculta en la informalidad de estos acuerdos.

\section{El TFUE y el intento de reforzar la participación de los parlamentos nacionales en el proceso legislativo en la UE}

El TFUE en sus protocolos $\mathrm{N}^{\circ} 1$ y $\mathrm{N}^{\circ} 2$ establece que los proyectos de acto legislativo deberán ser enviados a las comisiones correspondientes de cada uno de los parlamentos nacionales de los Estados miembros para que sean analizadas a la luz de los principios de subsidiariedad y proporcionalidad. Con este mandato se busca una mayor participación de los parlamentos nacionales en el proceso legislativo en la UE, no solamente para controlar el respeto a los principios de subsidiariedad y proporcionalidad sino también para reforzar la legitimidad democrática del proceso legislativo en la UE.

Sin embargo, como ya se ha establecido en los apartados anteriores, las dinámicas informales de los "diálogos tripartitos" y de los "acuerdos tempranos" dificultan la correcta participación de los parlamentos nacionales en el proceso legislativo, dado que la información con la que estos cuentan al recibir los proyectos de acto legislativo, en algunos casos puede terminar no siendo la misma información que se debate en estas reuniones informales, pues en estos acuerdos se pueden introducir cambios al proyecto 
de acto legislativo. Además de esto, en los casos en que la legislación es adoptada por la vía de "acuerdos tempranos", los parlamentos nacionales no han contado con el tiempo suficiente para dirigir sus recomendaciones a las instituciones de la UE (Farrell y Héritier, 2003). Con esto se hace evidente la inutilidad del esfuerzo que hace el TFUE por reforzar la participación de los parlamentos nacionales en el proceso legislativo de la UE.

\section{El TFUE y los acuerdos informales: Democracia vs. Eficacia}

Teniendo en cuenta el propósito y el análisis que se ha hecho a lo largo de este estudio, se puede afirmar que las incorporaciones que hace el TFUE no permiten superar el déficit democrático en el desarrollo del proceso legislativo al interior de la UE, y no lo permiten porque estas reformas no ejercen ningún tipo de control sobre los procedimientos informales que surgen tras la entrada en vigor del TUE y que cada vez más dominan el procedimiento legislativo ordinario en la UE.

Entendiendo el funcionamiento de los "diálogos tripartitos" y la naturaleza de los "acuerdos tempranos", se hace visible cómo la urgencia de aumentar la eficacia de los procesos legislativos en la UE, se antepone a necesidad de legitimación democrática de los mismos.

Este privilegio de la eficacia en detrimento de la democracia al interior de la UE, concuerda con lo que Beck y Grande (2006) han descrito como una de las dolencias que padece Europa y que le impide una mayor profundización en su integración política: la falacia tecnocrática. En ese sentido, se puede afirmar de acuerdo con Beck y Grande, que el desarrollo de las prácticas informales en el proceso legislativo de la UE responden a estrategias tecnocráticas caracterizadas por una "racionalidad funcional" (p. 211) cuyo objetivo es aumentar la eficacia del proceso legislativo al interior de la UE, a pesar de que van en detrimento de la democracia, pues se asume que este mismo proceso (legislativo) puede llevarse a cabo sin la correcta representación democrática de los ciudadanos europeos.

Teniendo en cuenta todo lo anterior, se puede afirmar que no importa cuántas reformas se lleven a cabo en los Tratados de la UE, si estas reformas no ejercen ningún tipo de control y regulación sobre las prácticas informales al interior del proceso legislativo en la UE, cualquier intento por otorgar legitimidad al proceso de toma de decisiones en la UE estará viciado desde un principio y esto constatará que las denuncias que se han planteado sobre el déficit democrático en la UE sigan siendo válidas.

\section{Conclusiones}

El proceso de construcción de la integración europea da cuenta desde sus inicios de una clara vocación federal. La identificación de la identidad europea a través del principio de unidad en la diversidad, la existencia de instituciones supranacionales a las que se les ha delegado poderes que antes eran de propiedad exclusiva de los Estados y que además son manifestación de un gobierno compartido reflejan esto. Pero esta vocación federal choca 
de frente con la creciente tendencia intergubernamental que domina el mismo proceso de integración de la UE: los Estados, celosos de perder poder frente a las instituciones supranacionales, procuran dominar este proceso conforme a sus propias preferencias.

La evolución que ha tenido el procedimiento legislativo ordinario de la UE es un claro ejemplo de lo anterior. La incorporación del PE como principal órgano de representación política directa en el proceso de aprobación legislativa generó tensiones al interior del Consejo, quien hasta la entrada en vigor del TUE, gozaba del privilegio de ser el principal tomador de decisión el interior de la UE. Estas tensiones derivaron en una serie de prácticas informales que se convirtieron en una clase de incentivos perversos para las dos instituciones. Mientras el Consejo busca una mayor eficacia del procedimiento legislativo ordinario, el PE busca un mejor posicionamiento a la hora de tomar decisiones al interior del mismo. Ambos incentivos están presentes en lo que ocurre al interior de los "diálogos tripartitos" y la aprobación legislativa mediante los "acuerdos tempranos", y su perversidad radica en que atentan directamente contra la legitimidad democrática de la UE.

El valor de la democracia es uno de los principios fundamentales sobre los que se estructura la UE. De ahí la razón por la cual cada vez que la UE busca profundizar su proceso de integración siempre se le esté demandando elementos que le permitan fortalecer su legitimidad democrática, como es el caso del fortalecimiento institucional del PE. Sin embargo, el carácter informal de los “diálogos tripartitos” y la aprobación mediante los "acuerdos tempranos" al interior del procedimiento legislativo ordinario, atentan de manera directa contra la institucionalidad del PE; si bien mediante las negociaciones de estos acuerdos logra un mayor empoderamiento en sus facultades legislativas, lo hace en detrimento de los principales elementos democráticos que él mismo está obligado a defender: la transparencia y la rendición de cuentas. Así, la informalidad de estas prácticas dificulta que los ciudadanos europeos tengan acceso a la información y con ello, que se permitan tener una opinión racional sobre lo que están haciendo sus representantes a nivel comunitario. De igual manera, al no haber información sobre lo que se debate y menos sobre quienes de manera particular lo hacen, es imposible que los ciudadanos europeos puedan hacerse una idea sobre cuáles son los intereses que están en juego; esto también les impide ejercer mecanismos de rendición de cuentas sobre sus representantes.

Finalmente, las reformas que contempla el TFUE con miras a fortalecer la legitimidad democrática en el proceso legislativo de la UE, como el aumento de los temas sobre los cuales se decidirá mediante el procedimiento legislativo ordinario, el mandato de apertura y transparencia para el Consejo y el PE en el ejercicio del procedimiento legislativo ordinario y el fortalecimiento de la relación de las instituciones europeas con los parlamentos nacionales durante el procedimiento legislativo ordinario, son insuficientes para superar el déficit democrático en el desarrollo del proceso legislativo al interior de 
la UE, pues estas reformas no ejercen ningún tipo de control sobre los procedimientos informales que surgen tras la entrada en vigor del TUE y que cada vez más dominan el procedimiento legislativo ordinario en la UE.

Así pues, mientras no se ejerza ningún tipo de control y regulación sobre las prácticas informales al interior del proceso legislativo en la UE, cualquier intento por otorgarle legitimidad estará viciado desde un principio, y como consecuencia de esto, el deterioro democrático de la UE será cada vez mayor.

\section{Referencias Bibliográficas}

Beck, U. y Grande, E. (2006). La Europa cosmopolita. Barcelona: Paidós.

Bonde, J. (2011). The European Union's Democratic Deficit: How to Fix It. Brown Journal of World Affairs, 17 (2), 147-162. Disponible en http://search.proquest. com/docview/914695678?accountid=13250.

Campbell, M. (2009). The Democratic Deficit in the European Union. Claremont-UC Undergraduate research Conference on the European Union. Disponible en: http://scholarship.claremont.edu/urceu/vol2009/iss1/5.

Cancela, C. (2001). El proceso de constitucionalización de la Unión Europea. De Roma a Niza. Santiago de Compostela: Universidad Santiago de Compostela.

Corbett, R., Jacobs, F., y Shackleton, M. (1995). The European Parliament. Londres: Longman Group.

Crombez, Ch. (2003). The Democratic Deficit in the European Union: ¿Much ado About Nothing? European Union Politics, 11 (4), 101-120. Disponible en: http://www. uk.sagepub.com/suder/Chapter\%204\%20-\%20Crombez.pdf.

Crum, B. (2005). Tailoring representative Democracy to the European Union: ¿Does the European Constitution Reduce the Democratic Deficit? European Law Journal, 11 (4). Disponible en: http://dare2.ubvu.vu.nl/bitstream/handle/1871/33820 /178754.pdf?sequence $=1$.

Dahl, R. (1994). A Democratic Dilemma: System Effectiveness versus Citizen Participation. Political Science Quarterly, 109 (1). 23-34. Disponible en: http://www. jstor.org/stable/2151659.

Díez-Moreno, F. (2006). Manual de derecho de la Unión Europea. Navarra: Thompson Civitas.

Elazar, D. (1993). The Federalist. Jerusalem Center for Public Affairs. Disponible en http://jcpa.org/dje/articles/federalist.htm. 
Farrell, H. y Héritier, A. (2003). The invisible transformation of codecision: problems of democracy legitimacy. Disponible en: http://www.sieps.se/sites/default/ files/9-20037.pdf.

Follesdal, A. y Hix, S. (2005). Why there is a Democratic Deficit in the EU: A Response to Majone and Moravcsik. European Governance Papers (EUROGOV), C-0502. Disponible en: http://www.connex-network.org/eurogov/pdf/egp-connexC-05-02.pdf.

Friedrich, C. (1973). Europa: el surgimiento de una nación. Madrid: Alianza.

García, E. (2001). Crisis de la representación política: las exigencias de la política de la presencia. Revista de Estudios Políticos, 111, 215-226. Disponible en: www.ugr. es/ eirene/actividades/miradasalmundo/sesion6/texto3.pdf

García, E. (2005). El significado de la representación política. Anuario de la Facultad de Derecho UAM. Disponible en: www.uam.es/otros/afduam/pdf/8/69oo844\%2O (109_120).pdf.

Godoy, O. (1998). Problemas contemporáneos de la democracia representativa. En: C. Jackisch (Comp.), Representación política y democracia (pp. 45-70). Buenos Aires: Konrad Adenauer Stiftung-CIDELA.

Habermas, J. (2009). iAy, Europa! Madrid: Trotta.

Habermas, J. (2010). La inclusión del otro. Barcelona: Paidós.

Held. D. (2007). Modelos de democracia. Madrid: Alianza.

Héritier, A. y Reh, Ch. (2011). Codecision and its Discontents: Intra-organization Politics and Institutional Reform in the European Parliament. Network of European Union Centers of Excellence. . Disponible en: http://euce.org/eusa/2011/ papers/7k_heritier.pdf

Hix, S. y Høyland, B. (2012). Sistema político de la Unión Europea. Madrid: McGraw- Hill.

Hoffmann, S. (1966). ¿Obstinate or Obsolate? The Fate of the Nation-State and the Case of Western Europe, Daedalus, 95 (3), 862-915. Disponible en: http://www.jstor. org/stable/20027004.

Kaelble, H. (2005). Caminos hacia la democracia: Los déficits democráticos de la Unión Europea. Madrid: Editorial Biblioteca Nueva.

Katz, R. (2001). Models of democracy: Elite Attitudes and the Democratic Deficit in the European Union. European Union Politics, 2 (1), 53-79. Disponible en http:// eup.sagepub.com/content/2/1/53.refs.html. 
Majone, G. (1998). Europe's 'Democratic Deficit': The Question of Standards. European Law Journal, 4 (1), 5-28. Disponible en: http://isites.harvard.edu/fs/docs/icb. topic162929.files/G_Democratic_Deficit/Majone.pdf.

Mangas, A. y Liñán, D. (2006). Instituciones y derecho de la Unión Europea. Madrid: Tecnos.

Manin, B. (1998). Los principios del gobierno representativo. Madrid: Alianza Editorial.

Manzanares, H. y Quentin, J. (1984). Un poco de historia. En: J. Subirats y P. Vilanova, (Eds.), El Parlamento Europeo (pp. 21 - 52). Barcelona: Ariel.

Mariscal, N. (2003). Teorías políticas de la integración europea. Madrid: Tecnos.

Martín y Pérez de Nanclares, J. y Urrea, M. (2010). Tratado de Lisboa. Madrid: Real Instituto Elcano-Marcial Pons.

Milev, M. (2004). A Democratic Deficit in the European Union? International Centre of European Information. Disponible en: http://www.ieei.eu/bibliotheque/ memoires/MILEV.pdf.

Monnet, J. (2008). Los Estados Unidos de Europa han comenzado. La Comunidad Europea del Carbón y el Acero. Discursos y alocuciones 1952-1954. Madrid: Instituto de Estudios Europeos-Ediciones Encuentro.

Morata, F. (1999). La Unión Europea. Barcelona: Ariel.

Moravcsik, A. (1991). Negotiating the Single European Act. En: R. Keohane, y S. Hoffmann (Eds.), The New European Community. Decisionmaking and Institutional Change (pp. 41-84). Boulder: Westview Press.

Moravcsik, A. (1993). Preferences and Power in the European Community: A Liberal Intergovernmentalist Approach. Journal of Common Market Studies, 31 (4), 473-524. Disponible en: http://www.princeton.edu/ amoravcs/library/preferences1.pdf.

Moravcsik, A. (1998). The Choice for Europe. Nueva York: Cornell University Press.

Moravcsik, A. (2002). In Defense of the 'Democratic Deficit': Reassessing Legitimacy in the European Union. Journal of Common Market Studies, 40 (4), 603-624. Disponible en: http://www.princeton.edu/ amoravcs/library/deficit.pdf.

Navarro, N. (1995). El Parlamento Europeo y poder normativo en la Unión Europea. Salamanca: Ediciones Universidad de Salamanca.

O’Donnell, G. (2001). La irrenunciabilidad del Estado de Derecho. Instituciones y Desarrollo, 8 (9). Disponible en: www.2.fices.unsl.edu.ar/ maestsei/apuntes/ O’Donnell.doc. 
Parlamento Europeo (2013). Reglamento. Disponible en: http://www.europarl.europa.eu/sides/getDoc.do?pubRef=-//EP//NONSGML+RULES-EP+20130521+ $\mathrm{O}+\mathrm{DOC}+\mathrm{PDF}+\mathrm{Vo} / /$ ES\&language $=\mathrm{ES}$.

Pitkin, H. (1967). The Concept of Representation. Berkeley: University of California Press.

Preciado, J. (2008). Retos, límites y aspiraciones de la representación democrática. Folios, 11 (9). Disponible en: www.iepcjalisco.org.mx/sites/default/files/ediciono9.pdf.

Przeworski, A. (1998). Democracia y representación. Revista del CLAD Reforma y Democracia. Disponible en: unpan1.un.org/intradoc/groups/public/documents/.../ cladoo30103.pdf.

Reh, Ch. et. al. (2010). The informal politics of legislation: explaning secluded decision - making in the European Union. Disponible en: http://papers.ssrn.com/sol3/ papers.cfm?abstract_id=1642265.

Salomón, M. (1999). La PESC y las teorías de la integración europea: las aportaciones de los 'nuevos intergubernamentalismos'. Revista CIDOB d'Aferes Internacionals, 45-46, 197-221. Disponible en: http://www.cidob.org/es/publicaciones/ articulos/revista_cidob_d_afers_internacionals/la_pesc_y_las_teorias_de_ la_integracion_europea_las_aportaciones_de_los_nuevos_intergubernamentalismos2.

Scharpf, F. (1999). Gobernar en Europa ¿̇eficaz y democráticamente? Madrid: Alianza Editorial.

Sidjanski, D. (1998). El futuro federalista de Europa. De los orígenes de la Comunidad Europea a la Unión Europea. Barcelona: Ariel.

Schuman, R. (2006). Por Europa. Madrid: Instituto de Estudios Europeos-Ediciones Encuentro.

Unión Europea (1951). Tratado constitutivo de la Comunidad Europea del Carbón y del Acero. Disponible en: http://eur-lex.europa.eu/LexUriServ/LexUriServ. do?uri=CELEX:11951K:ES:PDF.

Unión Europea (1992). Tratado de la Unión Europea. Disponible en: http://eur-lex. europa.eu/LexUriServ/LexUriServ.do?uri=OJ:C:1992:191:FULL:ES:PDF.

Unión Europea (2012). Versión consolidada del Tratado de Funcionamiento de la Unión Europea. Disponible en: http://eur-lex.europa.eu/LexUriServ/LexUriServ.do? uri=OJ:C:2012:326:FULL:ES:PDF. 
Warleigh, A. (2003). Democracy and the European Union. Londres: SAGE Publications.

Weiler, J., Haltern, U. y Mayer, F. (1995). European Democracy and its Critique. Five Uneasy Pieces (Working Paper RSC No. 95/11). Disponible en: http://cadmus. eui.eu/bitstream/handle/1814/1386/95_11.pdf?sequence=1. 
